\title{
Study of total phenolic and flavonoid content, antioxidant activity and antimicrobial properties of medicinal plants
}

\begin{abstract}
The anti-oxidant activity and total phenolic content of alcoholic extracts from seven medicinal plants (Asparagus racemosus, Ocimum sanctum, Cassia fistula, Piper betel, Citrus aurantifolia, Catharanthus roseus, and Polyalthia longifolia) were evaluated by using a model system consisting of $\beta$-carotene, DPPH free radical and Folin-Ciocalteu method. The total Phenolic content of the extracts was determined spectrophotometrically according to the Folin-Ciocalteu procedure and ranged from $366 \mathrm{mg} / 100 \mathrm{~g}$ to $212 \mathrm{mg} / 100 \mathrm{~g}$ on fresh weight basis. The total flavanoid content of extracts determined by Aluminium chloride colorimetric assay and ranged from $39.84 \mathrm{mg} / 100 \mathrm{~g}$ to $15.94 \mathrm{mg} / 100 \mathrm{~g}$ of fresh weight. The highest antioxidant activity was demonstrated by Citrus auantifolia $(87.05 \%)$ followed by Ocimum sanctum $(81.80 \%)$ and Catharanthus roseus (71.4\%). The highest tannin content was found to be in Catharanthus roseus $(7.14 \%$ ) while in case of anthocyanin content the highest value was found to be in Polyalthia longifolia $(0.65 \mathrm{mg} / 1)$. As far as antimicrobial activity is concerned, Ocimum sanctum and Citrus aurantifolia were found to be most potent against Escherichia coli and Staphylococcus aureus whereas Piper betel showed no effect. Except Piper betel all the extracts were able to inhibit the two bacterial strains and the zone of inhibitions ranged from $19.6 \mathrm{~mm}$ to $13.5 \mathrm{~mm}$. The minimum inhibitory concentration against $E$. coli in case of Ocimum sanctum is $10 \%$ and against S. aureus it is $20 \%$ while in case of Citrus aurantifolia extracts were active even at $10 \%$ concentration for E. coli and $15 \%$ for $S$. aureus.
\end{abstract}

Keywords: anti-oxidant activity, phenolic content, flavanoid content, antimicrobial activity, minimum inhibitory concentration
Volume I Issue I - 2014

\section{Sarabjot Kaur,' Poonam Mondal'}

'Department of Pharmaceutical Sciences, Assam University, India ${ }^{2}$ Department of Biotechnology, Lovely Professional University, India

Correspondence: Sarabjot Kaur, Faculty of Biochemistry, Department of Pharmaceutical Sciences, Assam University, Silchar, Silchar-788 007, Assam, India, Tel +91-9435025983, Fax 03842266173, Email sarabjot.sohal@gmail.com

Received: April 19, 2014 | Published: May 09, 2014

\section{Introduction}

Medicinal plants, as source of remedies, are widely used as alternative therapeutic tools for the prevention or treatment of many diseases. The recent studies have investigated that the antioxidant effect of plant products is mainly attributed to phenolic compounds such as flavonoids, phenolic acids, tannins etc. ${ }^{1,2}$ Accumulation of free radicals can cause pathological conditions such as ischemia, asthma, arthritis, inflammation, neuro-degenertion, Parkinson's diseases, mongolism, ageing process and perhaps dementia. Natural antioxidants have become the target of a great number of research studies in finding the sources of potentially safe, effective and cheap antioxidants. ${ }^{3}$ Herbal drugs containing free radical scavengers are known for their therapeutic activity. ${ }^{4}$

Seven medicinal plants were selected for this study (Asparagus racemosus, Ocimum sanctum, Cassia fistula, Piper betel, Citrus aurantifolia, Catharanthus roseus, and Polyalthia longifolia) considering their medicinal properties. Medicinal plants are considered as clinically effective and safer alternatives to the synthetic antibiotics. ${ }^{5}$ Plants produce a very impressive array of antioxidant compounds that includes carotenoids, flavonoids, ascorbic acid, etc to prevent the oxidation of the susceptible substrate. Antioxidants are usually applied to prevent lipid peroxidation in the food industries. ${ }^{6,7}$ In this investigation, along with Phenolic and antioxidant properties of selected plants, antimicrobial activity of plant extracts against Escherichia coli and Staphylococcus aureus are also tested.

\section{Materials and methods}

\section{Plant material used}

The leaves of medicinal plants (Asparagus racemosus, Ocimum sanctum, Cassia fistula, Piper betel, Citrus aurantifolia, Catharanthus roseus, and Polyalthia longifolia) were obtained from Lovely Professional University campus and Defense Colony, Jalandhar of Punjab (India).

\section{Microorganisms procured and their maintenance}

For determination of antimicrobial activity the test organisms Staphylococcus aureus (MTCC96) and Escherichia coli (MTCC723) were procured from IMTECH, Chandigarh. The selective media used for growth of E. coli was Eosin Methylene Blue (EMB) media and for S. aureus it was Manitol Salt Agar (MSA) media. For the antimicrobial test Mueller Hinton Agar Medium was used. Inoculated bacterial cultures were incubated at $37^{\circ} \mathrm{C}$ for $24 \mathrm{hr}^{8}$

\section{Chemicals}

Sodium acetate, potassium chloride, 2-diphenyl-1-picrylhydrazylhydrate (DPPH), Folin-Ciocalteu reagent, catechol, beta carotene, Tween-20, sodium carbonate, sodium hydroxide, acetone, butanol, chloroform, ethanol and aluminium chloride were obtained from purchased from E-merck, Mumbai, India. Manitol salt, Mueller Hinton Agar and Eosin Methylene Blue were obtained from Hi-media Ltd. All the chemicals used were of analytical grade. 


\section{Preparation of plant samples}

The plant leaves were cleaned and cut into small pieces. Samples $(2 \mathrm{~g})$ were homogenized in $80 \%$ aqueous ethanol at room temperature and centrifuged at $10,000 \mathrm{rpm}$ for $15 \mathrm{~min}$ and the supernatant was preserved for estimation of various parameters. The residue was reextracted twice with $80 \%$ ethanol and supernatants were pooled, put into evaporating dishes and evaporated to dryness at room temperature. Residue was dissolved in $5 \mathrm{ml}$ of distilled water and stored at $4-8^{\circ} \mathrm{C}$ in a refrigerator for further analysis. ${ }^{9}$

\section{Preparation of plant samples for antimicrobial activity}

Twenty five grams of the plant leaves were weighed and then grinded with methanol. The leaves were then soaked into $50 \mathrm{ml}$ methanol (98\%) for 72hours. Then the methanol was allowed to evaporate in water bath. The concentrated methanolic extracts were weighed and preserved for further use. ${ }^{10}$

\section{Determination of total phenolic, total flavonoid, total anthocyanin and tannin content}

Total Phenolic Content was determined by using Folin-Ciocalteu method with catechol as standard. One-hundred microlitres of each sample extract was diluted to $3 \mathrm{ml}$ with distilled water and $0.5 \mathrm{ml}$ of Folin-Ciocalteu reagent was added. After $3 \mathrm{~min}$, $2 \mathrm{ml}$ of $20 \%$ sodium carbonate was added and the contents were mixed thoroughly. The colour was developed and absorbance measured at $650 \mathrm{~nm}$ in spectrophotometer (Shimadzu UV-1800) after 60min. ${ }^{11}$ Different concentrations of catechol solution $(5 \mathrm{mg} / 100 \mathrm{ml})$ were used to plot the calibration curve. Results were expressed asmg catechol/100g of fresh weight material using the

Formulae equivalent:

Where $\mathrm{A}_{650}$ is absorbance at $650 \mathrm{~nm}, \mathrm{~V}$ is volume made up, D.F is

$$
\frac{\text { O.D (Sample }) X A_{650} X V X \text { D.FX100 }}{w X 1000}
$$

dilution factor and $\mathrm{w}$ is weight of sample in grams

Total Flavanoid Content was determined by aluminum chloride colorimetric assay. ${ }^{12}$ An aliquot $(1 \mathrm{ml})$ of extract or a standard solution of catechol $(10 \mathrm{mg} / 100 \mathrm{ml})$ was added to $10 \mathrm{ml}$ flask containing $4 \mathrm{ml}$ of distilled water. To this $0.3 \mathrm{ml} 5 \% \mathrm{NaNO}_{2}$ was added. After 5 minutes, $0.3 \mathrm{ml}$ of $10 \% \mathrm{AlCl}_{3}$ was added. After $6 \mathrm{~min}, 2 \mathrm{ml}$ of $1 \mathrm{M} \mathrm{NaOH}$ was added and the total volume was made up to $10 \mathrm{ml}$ with distilled water. Absorbance was read at $510 \mathrm{~nm}$ with a spectrophotometer.

Total monomeric Anthocyanin (TA) was estimated by $\mathrm{pH}-$ differential method. ${ }^{13}$ Two dilutions of the sample were prepared, one with potassium chloride buffer, $\mathrm{pH} 1.0$, and the other with sodium acetate buffer, $\mathrm{pH}$ 4.5. These dilutions were left to equilibrate for $15 \mathrm{~min}$. The absorbance of each dilution at $520 \mathrm{~nm}$ and at $700 \mathrm{~nm}$, against a blank cell filled with distilled water was measured. Calculation of TA concentration is based on the molecular weight (MW) and the molar extinction coefficient $(\varepsilon)$ (26900) of cyanidin3-glucoside $(449.2 \mathrm{~g})$, the most common anthocyanin in nature. ${ }^{1}$ The absorbance of sample (A) was calculated as follows:

$$
\begin{gathered}
A=\left(A_{520}-A_{700}\right) p H 1.0-\left(A_{520}-A_{700}\right) p H 4.5 \\
T A(m g / L)=\frac{(A X M W X D F X 1000)}{(\varepsilon X 1)}
\end{gathered}
$$

Determination of condensed tannin content (proanthocyanidins) (TC) was determined by the method of Porter et al. ${ }^{14}$ In a glass test tube, $0.50 \mathrm{ml}$ of the tannin extract was diluted with $70 \%$ acetone. The quantity of acetone was large enough to prevent the absorbance $(550 \mathrm{~nm})$ in the assay from exceeding 0.6. It will depend on the quantity of condensed tannin expected in the sample, and occasionally will need to be determined by trial and error. To the tubes $3.0 \mathrm{ml}$ of the butanol- $\mathrm{HCl}$ reagent and $0.1 \mathrm{ml}$ of the ferric reagent was added. The contents in the tubes were evenly mixed by vortex mixer. The mouth of each tube was covered and the tubes were put in a boiling water bath for $60 \mathrm{~min}$. The tubes were allowed to cool and absorbance was recorded at $550 \mathrm{~nm}$. For each sample mixture comprising $0.5 \mathrm{ml}$ of the extract, $3 \mathrm{ml}$ of butanol and $0.1 \mathrm{ml}$ of the ferric reagent were used.

Condensed tannins is expressed as leucocyanidin equivalent (460) and calculated by the formula:

$$
\frac{A_{550} \times 78.26 \times D F}{\% \text { Tannin content }}
$$

\section{Beta carotene bleaching method}

$\beta$-Carotene (2mg ) was dissolved in $20 \mathrm{ml}$ of chloroform. A $4 \mathrm{ml}$ aliquot of the solution was added to a conical flask with $40 \mathrm{mg}$ linoleic acid and 400mg Tween-40. Chloroform was removed with a rotary evaporator at $50^{\circ} \mathrm{C}$. Oxygenated distilled water $(100 \mathrm{ml})$ was added to the $\beta$-carotene emulsion mixed well and aliquots $(3 \mathrm{ml})$ of the oxygenated $\beta$-carotene emulsion and $0.2 \mathrm{ml}$ of alcoholic extracts were placed in capped culture tubes and mixed well. The tubes were immediately placed in a water bath (Optics technology) and kept at $50^{\circ} \mathrm{C}$ for 10 minutes. Oxidation of the $\beta$-carotene emulsion was monitored spectrophotometrically, taking absorbance at $470 \mathrm{~nm}$ for $100 \mathrm{~min}$. A control consisted of $0.2 \mathrm{ml}$ distilled water instead of plant leaf extracts. ${ }^{15}$

Antioxidant activity was expressed as per cent inhibition relative to control using the equation below:

$$
1-\frac{\left(A_{\text {omin }}-A_{100 \min }\right) X 100}{A_{\text {omin }}-A_{100 \min }}
$$

\section{DPPH scavenging method}

DPPH scavenging activity (\%) was determined following the method of Thirunavakkarasu et al. ${ }^{16}$ To $50 \mu 1$ of samples, $950 \mu 1$ of $90 \mu \mathrm{M}$ DPPH (2,2-diphenyl-1-picrylhydrazyl) solution was added and made up to a final volume of $4 \mathrm{ml}$ with $95 \%$ ethanol. After the mixtures were vigorously shaken, they were incubated at room temperature for 2 hours in dark. The reduction of solution colour caused by free radicals (DPPH) was measured at $515 \mathrm{~nm}$ using a spectrophotometer. The capability of samples to reduce DPPH was determined by sample colour reduction effect with control (mixture without the sample) using following equation and expressed in $\%$ values:

$$
=1-\frac{A_{\text {Sample }}}{A_{D P P H \text { Solution }}}
$$

\section{Agar well diffusion assay}

The antimicrobial activity was measured by Agar well diffusion assay. ${ }^{17}$ The plant extract were allowed to diffuse out into the medium and interact in a plate freshly seeded with the test organisms. Petri plates containing $20 \mathrm{ml}$ Mueller Hinton medium were seeded with the bacterial strains. Each labeled medium plate was uniformly 
inoculated with a test organism by using a sterile cotton swab rolled in the suspension to streak the plate surface in a form that lawn growth can be observed. Wells were punchered and $100 \mu$ l of the methanolic plant extracts were added. The plates were then incubated at $37^{\circ} \mathrm{C}$ for 24hours. Erythromycin $(0.05 \%)$ was used as positive control and analysis was done in triplicates. The antibacterial activity was assayed by measuring the diameter of the inhibition zone formed around the well. The diameter of zone of inhibition can be measured in millimeters. ${ }^{18}$

\section{Determination of minimum inhibitory concentration (MIC) of crude methanoic extracts}

The minimum inhibitory concentration was determined of those plant methanolic extracts which showed significant zones of inhibition against tested microorganisms (Asparagus racemosus, Ocimum sanctum, Cassia fistula, Citrus aurantifolia, Catharanthus roseus, and Polyalthia longifolia). Different dilutions (20,40,60, and 80$) \%$ of the plant extracts were assayed against the test organisms. Distilled water was used as negative control. The minimum inhibitory concentration was defined as the lowest concentration able to inhibit any visible bacterial growth. ${ }^{19}$ Piper betel was unable to show any significant effect on the test organisms, so its MIC was not determined. The extracts which exhibited zone of inhibition at even $20 \%$ concentration, they were being tested at lower concentrations viz. 5, 10 and $15 \%$.

\section{Results and discussion}

The amount of total phenolics content (TPC) is expressed asmg/100g of fresh weight (Table 1). Citrus aurantifolia, Asparagus racemosus, Ocimum sanctum showed maximum and Piper betel showed the minimum phenolic content among the selected extracts. Content varied widely among the samples and ranged from $366 \mathrm{mg} / 100 \mathrm{~g}$ to $212 \mathrm{mg} / 100 \mathrm{~g}$ of fresh weight. Ocimum spp. showed high phenolic content according to the results by Veeru et al., ${ }^{20}$ while Asparagus racemosus is also having comparable phenolic content contributing to its medicinal uses ${ }^{21}$ Citrus aurantifolia is reported to have comparatively higher phenolic content as per the study conducted by Ahmed et al., ${ }^{22}$ Citrus aurantifolia, Cassia fistula and C. roseus showed maximum and Asparagus racemosus showed the minimum flavonoid content among the extracts (Table 1). Ghafar et al. ${ }^{23}$ also found the flavonoid content of Citrus aurantifolia to be the highest. The total Flavonoid Content varied widely among the samples and ranged from $39.84 \mathrm{mg} / 100 \mathrm{~g}$ to $15.94 \mathrm{mg} / 100 \mathrm{~g}$ of fresh weight. Figures 1 shows the comparative $\beta$-carotene bleaching rates of the control and plant extracts. It shows a decrease in absorbance of $\beta$-carotene in the presence of different extracts due to the oxidation of $\beta$-carotene and linoleic acid. This indicates that all tested extracts possessed antioxidant capacity. All plant extracts showed moderate to high antioxidant capacity. The highest antioxidant activity was demonstrated by Citrus aurantifolia (87.05\%) followed by Ocimum sanctum (81.80\%). Catharanthus roseus (71.4\%), Cassia fistula $(77.8 \%)$ \& Polyalthia longifolia $(73.01 \%)$ showed moderate antioxidant activity, whereas Piper betel (52.4\%) and Asparagus racemosus $(59.94 \%)$ exhibited comparatively low activity. Yao et al., ${ }^{24}$ also reported the very high antioxidant activity of Citrus aurantifolia and suggest major contribution of non-vitamin factors to total in vitro antioxidant potency of C. aurantifolia. Chu et al., ${ }^{25}$ also reported to have similar results regarding antioxidant activity of Asparagus racemosus. Rosmarinic acid present in the chemical composition of Ocimum sanctum acts as the powerful antioxidant. ${ }^{26}$
DPPH scavenging ability of seven medicinal plants were screened in ethanol solvent system as shown in Figure 2. Polyalthia longifolia leaf $(76.84 \%)$ showed strong inhibition of DPPH radical followed by the leaf extract of Cassia fistula with $75.78 \%$ inhibition and Ocimum sanctum leaf $(74.73 \%)$, while others exhibited the DPPH radical scavenging capacity ranging from $35-65 \%$ in ethanolic solvent. The high scavenging activity of Polyalthia longifolia is also being supported by the work of Mukherjee et al., ${ }^{27}$ When total anthocyanin content was estimated, the highest was found to be in Polyalthia longifolia $(0.65 \mathrm{mg} / \mathrm{l})$ and minimum in Citrus aurantifolia $(0.04 \mathrm{mg} / \mathrm{l})$ (Table 2). This may be due to the deep green color of Polyalthia longifolia leaves. Tannin was estimated as percentage dry matter, the highest was found to be in Catharanthus roseus (7.14\%) and lowest in Citrus aurantifolia (2.0\%) (Table 2). Although tannins in general exhibit antioxidant activity specific research is needed to test the relationship between tannin content and antioxidant activity.

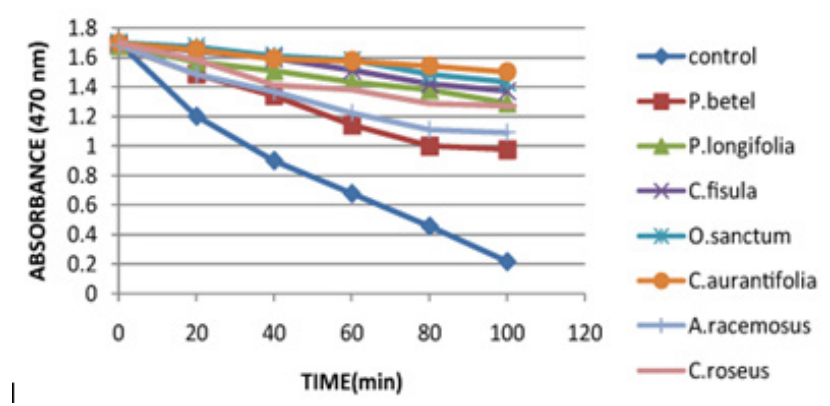

Figure I Antioxidant activity (beta carotene assay) of leaf extracts.

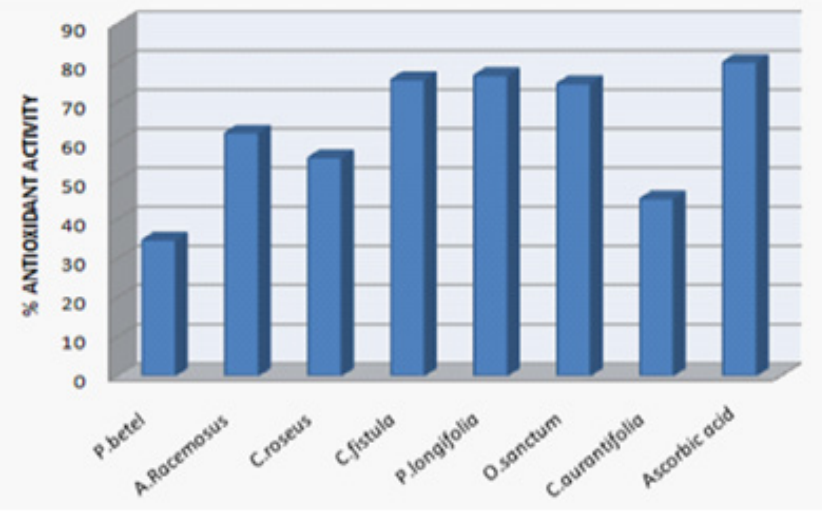

Figure 2 Antioxidant activity (DPPH scavenging method) of leaf extracts.

Table I Total Phenolic and flavanoid content of medicinal plant samples

\begin{tabular}{lll}
\hline Times & $\begin{array}{l}\text { Total phenolic content } \\
(\mathbf{m g} / \mathbf{1 0 0} \mathbf{g})\end{array}$ & $\begin{array}{l}\text { Total flavanoid } \\
\text { content } \\
(\mathbf{m g} / 100 \mathrm{~g})\end{array}$ \\
\hline P.betel & $212 \pm 0.50$ & $39.84 \pm 0.15$ \\
A.racemosus & $365 \pm 0.45$ & $15.94 \pm 0.10$ \\
C.roseus & $285 \pm 0.30$ & $41.68 \pm 0.25$ \\
C.aurantifolia & $366 \pm 0.13$ & $39.03 \pm 0.20$ \\
C.fistula & $264 \pm 0.52$ & $38.15 \pm 0.19$ \\
O.sanctum & $365 \pm 0.25$ & $20.50 \pm 0.21$ \\
P.longifolia & $244 \pm 0.60$ & $27.11 \pm 0.30$ \\
\hline
\end{tabular}

Data expressed as mean $\pm \mathrm{SE}$. 


\section{Relationship between total phenolic content and antioxidant activity of medicinal plants}

The anti-oxidant activity of extracts could not be explained just on the basis of their phenolic content but also required their proper characterization. This lack of relationship is in agreement with other literature..$^{28}$ It is known that only flavonoids with a certain structure and particularly hydroxyl position in the molecule can act as proton donating and show radical scavenging activity. ${ }^{29,30}$ Furthermore, the extracts are very complex mixtures of many different compounds with distinct activities. Our study is in agreement with Sengul et al., ${ }^{31}$ which reported no correlation between total phenolic content and antioxidant capacities of a number of medicinal plant extracts no correlation between total phenolic content and antioxidant capacity in our plant samples is possible owing to the presence of the following antioxidant capacity observed was not solely from the Phenolic contents, but could possibly be due to the presence of some other phytochemicals such as ascorbic acid, tocopherol and pigments etc which also contribute to the total antioxidant capacity. Also, phenolic content determined according to the Folin-Ciocalteu method is not an absolute measurement of the amount of phenolic materials. Different types of phenolic compounds have different antioxidant activities, which is dependent on their structure. The extracts possibly contain different type of phenolic compounds, which have different antioxidant capacities.

Table 2 Anthocyanin content and percentage tannin content of medicinal plant samples

\begin{tabular}{lll}
\hline Plant sample & $\begin{array}{l}\text { Anthocyanin content } \\
(\mathbf{m g} / \mathbf{l})\end{array}$ & $\begin{array}{l}\text { Percentage } \\
\text { Tannin content }\end{array}$ \\
\hline P.betel & 0.134 & 14.6 \\
A.racemosus & 0.13 & 3.76 \\
C.roseus & 0.34 & 7.14 \\
C.aurantifolia & 0.04 & 2.0 \\
C.fistula & 0.62 & 13.6 \\
O.sanctum & 0.37 & 14.37 \\
P.longifolia & 0.65 & 9.74 \\
\hline
\end{tabular}

\section{Antimicrobial activity}

In the present study, methanolic leaf extracts of seven medicinal plants were investigated against two bacterial species (Staphylococcus aureus and Escherichia coli). Some extracts had conspicuous zone of inhibition while some had moderate or little or no zone of inhibition. Methanoic extracts of Asparagus racemosus, Ocimum sanctum, Cassia fistula, Citrus aurantifolia, Catharanthus roseus and Polyalthia longifolia were active against Staphylococcus aureus (gram positive) and Escherichia coli (gram negative). Piper betel was inactive against both $E$. coli and $S$. aureus. Table 3 summarizes the microbial growth inhibition of methanolic extracts of the plant species and their MIC. Out of the seven plants, Ocimum sanctum was found to be most potent against all the microbes showing $19.6 \mathrm{~mm}$ and $17.6 \mathrm{~mm}$ zone of inhibition against $S$. aureus and $E$. coli respectively whereas Cassia fistula showed comparatively lower effect of $13.5 \mathrm{~mm}$ and $14.6 \mathrm{~mm}$ respectively. The study done by Joshi et al., ${ }^{32}$ also exhibits comparable inhibition against $S$. aureus by Ocimum sanctum. Citrus aurantifolia has shown $16.3 \mathrm{~mm}$ of inhibition zone against $S$. aureus, which is similar to the study conducted by Penecilla et al., ${ }^{33}$ Onyeagba et al., ${ }^{34}$ also supports the strong inhibition demonstrated C. aurantifolia (18mm zone of inhibition). Study conducted by Lawrence et al., ${ }^{35}$ $\left(19 \mathrm{~mm}\right.$ inhibition observed) and Goyal et al., ${ }^{36}$ (zone of inhibition $18.5 \mathrm{~mm})$ is also in agreement with this study about antimicrobial activity of Ocimum sanctum. The antibacterial activities of medicinal plants are attributed due to the presence of flavonoids, tannins and steroidal alkaloids. ${ }^{37}$ In Ocimum sanctum carvacrol and terpene are the antibacterial agents present. Sesquiterpene and caryophyllene also severs the same purpose. This constituent is FDA approved food additive which is naturally present in Ocimum spp. ${ }^{26}$ The zone of inhibitions observed in case of Asparagus racemosus is also observed by Sinha et al., ${ }^{38}$ against $E$. coli and $S$. aureus.

Table 3 Antimicrobial activity of the Extracts Data expressed as mean \pm SE, ---- showed no significant effect of extract on the microorganisms, -NA- not applicable

\begin{tabular}{|c|c|c|c|c|}
\hline \multirow{2}{*}{$\begin{array}{l}\text { Plant } \\
\text { species }\end{array}$} & \multicolumn{2}{|c|}{ Staphylococcus aureus } & \multicolumn{2}{|l|}{ Escherichia coli } \\
\hline & $\begin{array}{l}\text { Zone of } \\
\text { Inhibition }\end{array}$ & MIC & $\begin{array}{l}\text { Zone of } \\
\text { Inhibition }\end{array}$ & MIC \\
\hline $\begin{array}{l}\text { Ocimum } \\
\text { sanctum }\end{array}$ & $19.6 \pm 0.33 \mathrm{~mm}$ & $10 \%$ & $17.6 \pm 0.41 \mathrm{~mm}$ & $20 \%$ \\
\hline $\begin{array}{l}\text { Citrus } \\
\text { aurantifolia }\end{array}$ & $16.33 \pm 0.40 \mathrm{~mm}$ & $10 \%$ & $17.3 \pm 0.40 \mathrm{~mm}$ & $15 \%$ \\
\hline $\begin{array}{l}\text { Asparagus } \\
\text { racemosus }\end{array}$ & $18.5 \pm 0.40 \mathrm{~mm}$ & $20 \%$ & $16.3 \pm 0.41 \mathrm{~mm}$ & $20 \%$ \\
\hline Cassia fistula & $13.5 \pm 0.7 \mathrm{~mm}$ & $60 \%$ & $14.6 \pm 0.41 \mathrm{~mm}$ & $60 \%$ \\
\hline $\begin{array}{l}\text { Catharanthus } \\
\text { roseus }\end{array}$ & $14.33 \pm 0.41 \mathrm{~mm}$ & $40 \%$ & $16.33 \pm 0.40 \mathrm{~mm}$ & $40 \%$ \\
\hline $\begin{array}{l}\text { Polyalthia } \\
\text { longifolia }\end{array}$ & $16.33 \pm 0.41 \mathrm{~mm}$ & $20 \%$ & $16.5 \pm 0.70 \mathrm{~mm}$ & $20 \%$ \\
\hline Piper betel & ---- & ------ & ---- & ----- \\
\hline Control & $23.5 \pm 0.42 \mathrm{~mm}$ & $-N A-$ & $19.8 \pm 0.40 \mathrm{~mm}$ & $-\mathrm{NA}-$ \\
\hline
\end{tabular}

Table 3 gives details of minimum inhibitory concentration against $S$. aureus and E. coli by the methanolic extracts. Ocimum sanctum is found to inhibit $S$. aureus at a concentration of $20 \%$ and $E$. coli at a concentration of $10 \%$ and C. aurantifolia inhibited $S$. aureus and $E$. coli at $15 \%$ and $10 \%$ concentration respectively, while the methanolic extracts of Cassia fistula was only able to inhibit E. coli and $S$. aureus at $60 \%$ concentration. Agarwal et al., ${ }^{39}$ found that Ocimum sanctum extracts can inhibit Streptococcus species at even $4 \%$ concentration. Methanolic extract of Polyalthia longifolia against E. coli and S. aureus was active at concentration of $40 \%$ and $60 \%$ respectively. Chanda et al. ${ }^{40}$ also found similar results for Polyalthia longifolia. The phytochemical study of Polyalthia longifolia leaves shows plant mainly contains tannins, phenolic acids, glycosides and steroids. Presence of flavonoids and tannins in Polyalthia longifolia are responsible for antibacterial activity. ${ }^{41}$

Phytochemical studies revealed the presence of phenolics, flavonoids, tannins, anthocyanins which contributes to the antimicrobial activity of these plants. In recent years multiple drug resistance in human pathogenic microorganisms has developed due to the indiscriminate use of commercial antimicrobial drugs commonly used in the treatment of infectious diseases, making it a global growing problem. In addition to this problem antibiotics are sometimes 
associated with adverse effects on host including hypersensitivity, immune suppression and allergic reactions..$^{42}$ Therefore, there is a need to develop alternative antimicrobial drugs for the treatment of infections obtained from various sources such as medicinal plants. The antibacterial activity found in this present study may be attributed to the presence of secondary metabolites of various chemical types present in the plant material either individually. The discovery of a potent remedy from plant origin will be great advancement in microbial infection therapies.

\section{Conclusion}

The present study reported the antioxidant activity, total phenolic and flavonoid contents of seven medicinal plants (Asparagus racemosus, Ocimum sanctum, Cassia fistula, Piper betel, Citrus aurantifolia, Catharanthus roseus, and Polyalthia longifolia). In order to realize the health benefits from potential plant sources, it is important to measure the anti-oxidant activity using various radicals and oxidation systems. Ocimum sanctum and Asparagus racemosus were found to possess the highest phenolic content while Citrus aurantifolia showed the highest antioxidant activity, followed by Ocimum sanctum, thus attributing to their use as medical plants. The two bacterial strains (Staphylococcus aureus and Escherichia coli) used in this experiment are responsible for an array of human diseases such as cholecystitis, urinary tract infection, skin infections etc. However, these human pathogenic strains were significantly inhibited by the methanolic leaf extracts of the medicinal plants. Ocimum sanctum and Citrus aurantifolia was most potent against the microorganisms, their extracts were effective even at 10\% concentration against Escherichia coli whereas against Staphylococcus aureus it was 20\% and 15\% concentration respectively. Therefore, the study provides support to the plant's traditional and alternative use against various diseases and infections. Further, the biomolecules present in the extract which are active against these microbes needs to be characterized. Use of natural products has been encouraged due to less or no side effects, cost effectiveness and development of resistance to conventional synthetic antibiotics. Hence, this study holds importance in using medicinal plants as an alternative source for treating various diseases. Additional information on the dietary intake of medicinal plants selected in this study, and enhancing their bioavailability after various processing operations need to be elucidated in future.

\section{Future work}

Extensive research in the area of isolation and characterization of the active principles of these plants are required so that better, safer and cost effective drugs for treating bacterial infections can be developed.

\section{Acknowledgements}

None.

\section{Conflict of interest}

The author declares no conflict of interest.

\section{References}

1. Nagavani V, Rao TR. Evaluation of antioxidant potential and qualitative analysis of major polyphenols by RP-HPLC in Nymphaea nouchali Burm flowers. International Journal of Pharmacy and Pharmaceutical Sciences. 2010;2(Suppl 4):98-104.
2. Cartea ME, Francisco M, Lema M, et al. Resistance of cabbage (Brassica oleracea capitata Group) crops to Mamestra brassicae. Journal of Economic Entomology. 2010;103(5):1866-1874.

3. Mundhe KS, Kale AA, Gaikwad SA, et al. Evaluation of phenol, flavonoid contents and antioxidant activity of Polyalthia longifolia. J Chem Pharm Res. 2011;3(1):764-769.

4. Hakiman M, Maziah M. Non enzymatic and enzymatic antioxidant activities in aqueous extract of different Ficus deltoidea accessions. Journal of Medicinal Plants Research 2009;3(3):120-131.

5. Solanki R. Some medicinal plants with antibacterial activity. International Journal of Comprehensive Pharmacy. 2010;1:10-15.

6. Qusti SY, Abo-khatwa AN, Lahwa MAB. Screening of antioxidant activity and phenolic content of some selected food items cited in the holy Quran. EJBS. 2010;2(1):40-51.

7. Javanmardi J, Stushnoff C, Locke E, et al. Antioxidant activity and total phenolic content of Iranian Ocimum accessions. Food Chemistry. 2003;83(4):547-550.

8. Rojas JR, Ochoa VJ, Ocampo SA, et al. Screening for antimicrobial activity of ten medicinal plants used in Colombian folkloric medicine:a possible alternative in the treatment of non-nosocomial infections. $B M C$ Complement Altern Med. 2006;6:2.

9. Thirumalaisamy R, Gowrishankar J, Suganthapriya S, et al. Genetic variability in Morus alba $L$ by Biochemical and Bioassay Methods for increased Silk Productivity. J Biomed Sci and Res. 2009;1(1):11-18.

10. Vimalraj TR, Kumar SS, Vadivel S, et al. Antibacterial effect of Cassia fistula extract on pathogenic bacteria of veterinary importance. Tamilnadu $J$ Veterinary \& Animal Sciences. 2009;5(3):109-113.

11. Singleton VL, Rossi JA. Colorimetry of total phenolics with phosphomolybdic-phosphotungstic acid reagents. Am J Enol Vitic. 1965;16(3):144-158.

12. Atanassova M, Georgieva S, Ivancheva K. Total phenolic and total flavonoid contents, antioxidant capacity and biological contaminants in medicinal herbs. Journal of the University of Chemical Technology and Metallurgy. 2011;46(1):81-88.

13. Lichtenthaler HK. Chlorophylls and carotenoids:Pigments of photosynthetic biomembranes. Methods in Enzymology. 1987; 148:350-382.

14. Porter LJ, Hrstich LN, Chan BG. The conversion of procyanidins and prodelphinidins to cyanidin and delphinidin. Phytochemistry. 1985;25(1):223-230.

15. Al-Saikhon MS, Howard LR, Miller JC. Anti-oxidant activity and total phenolics in different genotypes of potato (Solanum tuberosum, L.). Journal of Food Science. 1995;60(2):341-343.

16. Thirunavakkarasu P, Ramanathan T, Ramkumar L, et al. Antioxidant Activity of Selected coastal Medicinal plants. World Journal of fish and Marine Sciences. 2010;2(2):134-137.

17. Perez C, Pauli M, Bazerque P. An antibiotic assay by the agarwell diffusion method. Acta Biologiae et Medecine Experimentalis. 1990;15:113-115.

18. Shakouie S, Eskandarinezhad M, Mokhtari H, et al. Antimicrobial efficacy of AH-Plus, adseal and endofill against Enterococcus faecalis-An in vitro study. African Journal of Microbiology Research. 2012;6(5):991-994.

19. Shahidi BGH. Evaluation of antibacterial properties of Iranian medicinal plants against Micrococcus aureus, Serratia marcescens, Klebsiella pneunomiae and Bordella bronchoseptica. Asian Journal of Sciences. 2004;3(1):82-86 
20. Veeru P, Kishor MP, Meenakshi M. Screening of medicinal plan extracts for antioxidant activity. Journal of Medicinal Plants Research. 2009;3(8):608-612.

21. Srivastava T. Study of composition, activity and phenolic content of herbal products. International Journal of Engineering Science and Technology. 2012;4(4):1412-1420.

22. Ahmed SH, Rocha JB. Antioxidant properties of water extracts for the Iraqi Plants Phoenix dactylifera, Loranthus europeas, Zingiber officinalisand Citrus aurantifolia. Modern Applied Science. 2009;3(3):161-166.

23. Ghafar MFA, Prasad KN, Weng KK, et al. Flavonoid, hesperidine, total phenolic contents and antioxidant activities from Citrus species. African Journal of Biotechnology. 2010;9(3):326-330.

24. Yao Y, Vieira A. Comparative antioxidant properties of Citrus species:evidence for potent, non-vitamin antioxidants in C. aurantifolia. International Journal of Food, Nutrition and Public Health. 2011;4:108-112.

25. Chu YH, Chang CL, Hsu HF. Flavonoid content of several vegetables and their antioxidant activity. Journal of the Science of Food and Agriculture. 2000;80(5):561-566.

26. Pattanayak P, Behera P, Das D, et al. Ocimum sanctum Linn. A reservoir plant for therapeutic applications:An overview. Pharmacogn Rev. 2010;4(7):95-105.

27. Mukherjee S, Dey A, Das T. In vitro antibacterial activity of $\mathrm{n}-\mathrm{Hexane}$ fraction of methanolic extract of Alstonia scholaris L. R.Br. Stem Bark against some multidrug resistant human pathogenic bacteria. European Journal of Medicinal Plants. 2012;2(1):1-10.

28. Ghasemi K, Ghasemi Y, Ebrahimzadeh AM. Antioxidant activity, phenol and flavonoid contents of 13 citrus species peels and tissues. PakJ Pharm Sci. 2009;22(3):277-281

29. Nickavar B, Kamalinejad M, Izadpanah H. In Vitro free radical scavenging activity of five Salvia species. Pak J Pharm Sci. 2007;20(4):291-294.

30. Wojdylo A, Oszmianski J, Czemerys R. Antioxidant activity and phenolic compounds in 32 selected herbs. Food Chemistry. 2007;105(3):940-949.

31. Sengul M, Yildiz H, Gungo N, et al. Total phenolic content, antioxidant and antimicrobial activities of some medicinal plants. Pak J Pharm Sci. 2009;22(1):102-106.
32. Joshi B, Lekhak S, Sharma A. Antibacterial property of different medicinal plants: Ocimum sanctum, Cinnamomum zeylanicum, Xanthoxylum armatum and Origanum majorana. Kathmandu University Journal of Science, Engineering and Technology. 20095(1):143-150.

33. Penecilla GL, Magno CP. Antibacterial activity of extracts of twelve common medicinal plants from the Philippines. Journal of Medicinal Plants Research. 2011;5(16):3975-3981.

34. Onyeagba RA, Ugbogu OC, Okeke CU, et al. Studies on the antimicrobial effects of garlic (Allium sativum Linn), ginger (Zingiber officinale Roscoe) and lime (Citrus aurantifolia Linn). African Journal of Biotechnology. 2004;3(10):552-554.

35. Jahan F, Lawrence R, Kumar V, et al. Evaluation of antimicrobial activity of plant extracts on antibiotic-susceptible and resistant Staphylococcus aureus strains. J Chem Pharm Res. 2011;3(4):777-789.

36. Goyal P, Kaushik P. In vitro evaluation of antibacterial activity of various crude leaf extracts of Indian sacred plant, Ocimum sanctum L. British Microbiology Research Journal. 2011;1(3):70-78.

37. Ghosh G, Subudhi BB, Badajena LD, et al. Antibacterial activity of Polyalthia longifolia var. angustifolia stem bark extract. International Journal of PharmTech Research. 2011;3(1):256-260.

38. Sinha NS, Biswas M. Effect of extracts from Asparagus racemosus willd root against pathogenic bacteria. International Journal of Applied Biology and Pharmaceutical Technology. 2011;2(3):312-314.

39. Agarwal P, Nagesh L, Murlikrishnan. Evaluation of the antimicrobial activity of various concentrations of Tulsi (Ocimum sanctum) extract against Streptococcus mutans: an in vitro study. Indian J Dent Res. 2012;21(3):357-359.

40. Chanda S, Nair R. Evaluation of antioxidant propery and toxicological assessment of Polyalthia longifolia var. pendula leaf against 91 clinically important pathogenic strains. Chinese Medicine. 2011;1:31-38.

41. Pradhan P, Jhajharia M, Chulet R, et al. Preliminary studies on effect of biodiversity on activity of Polyalthia longifolia. Pharmacologyonline. 2011;2:11-15.

42. Khanahmadi M, Rezazadeh $\mathrm{SH}$, Taran M. In vitro antimicrobial and antioxidant properties of Smyrnium cordifolium Boiss. (Umbelliferae) extract. Asian Journal of Plant Science. 2010;9(2):99-103. 